Revista Española de Derecho Internacional Sección ESTUDIOS Vol. 67/2, julio-diciembre 2015, Madrid, pp. 83-109 http://dx.doi.org/10.17103/redi.67.2.2015.1.03 (C) 2015 Asociación de Profesores de Derecho Internacional y Relaciones Internacionales ISSN: 0034-9380; E-ISSN: 2387-1253

\title{
FUNCIONES DE LAS CLÁUSULAS DE EXCEPCIÓN EN EL PROCESO DE LOCALIZACIÓN DE LA NORMA DE CONFLICTO
}

\author{
Ana FERNÁNDEZ PÉREZ \\ Profesora asociada de Derecho internacional privado \\ Universidad de Castilla-La Mancha \\ Acreditada como Contratada doctora
}

SUMARIO: 1. EL PROCESO DE FLEXIBILIZACIÓN DEL DERECHO APLICABLE.-1.1. Ampliación de las facultades del juez en el proceso de localización.-1.2. Hacia la aplicación de la «ley más estrechamente vinculada».-2. CLÁUSULAS DE EXCEPCIÓN DE ALCANCE GENERAL.-2.1. Manifestaciones.-2.2. Caracterización.-2.3. Consideraciones críticas.-3. CLÁUSULAS DE EXCEPCIÓN Y ESPECIALIZACIÓN NORMATIVA.-3.1. Vinculación al mecanismo de localización.-3.2. Obligaciones.-3.2.1. Obligaciones contractuales.-3.2.2. Obligaciones extracontractuales.-3.3. Persona.-3.4. Familia y sucesiones.-4. LA CLÁUSULA DE EXCEPCIÓN COMO MECANISMO DE REALIZACIÓN DE OBJETIVOS MATERIALES.

\section{EL PROCESO DE FLEXIBILIZACIÓN DEL DERECHO APLICABLE}

\subsection{Ampliación de las facultades del juez en el proceso de localización}

1. La generalización de la codificación estatal del DIPr ha coincidido con una etapa donde el tradicional mecanismo de designación del Derecho aplicable, basado en la norma de conflicto, experimentaba un fuerte movimiento de renovación en torno a sus posibilidades de flexibilización ${ }^{1}$. El nuevo dise-

\footnotetext{
1 HaY, P., «Flexibility Versus Predictability and Uniformity in Choice of Law. Reflection on Current European and United States Conflicts Laws», Recueil des Cours, t. 226, 1991, pp. 281 y ss.
} 
ño de la norma de conflicto multilateral, elevado a la categoría de paradigma en los años noventa del pasado siglo $^{2}$, ha condicionado la reflexión teórica del DIPr y sus posibilidades reguladoras, convirtiéndose en un sector particularmente necesitado de una labor interpretativa, sustentada en el discurso práctico o argumentativo ${ }^{3}$.

Tras el debate doctrinal, en torno al pluralismo metodológico, al que siguió otro centrado en la concepción sustancial del conflicto de leyes ${ }^{4}$, la reflexión teórica ha contado con desarrollos importantes ${ }^{5}$, como el denominado análisis en dos escalones, o el derivado de la necesidad de incorporar elementos de corrección o de flexibilización al nuevo modelo conflictual. Nuestro propósito es la realización de unas modestas reflexiones en torno a este último debate, a cuyo frente se alzan las denominadas «cláusulas de excepción».

2. Dentro de las corrientes del denominado pluralismo metodológico ${ }^{6}$, y al margen de la incidencia de las llamadas normas de policía respecto de las cuales se quiso ver un punto de encuentro entre el DIPr continental y los desarrollos teóricos basados en las doctrinas americanas del governmental interest analysis ${ }^{7}$, durante un cierto periodo se asistió a una aceptación de posiciones unilateralistas que sugerían aplicar con carácter general la ley del foro de suerte que, desde la perspectiva unitaria apuntada por J. D. González Campos $^{8}$, la ley aplicable fuese la del tribunal que conociese del caso con la consiguiente coincidencia de la competencia legislativa y de la competencia judicial. No obstante, esta tendencia, legeforista, de hondo contenido dogmático, pese a su tendencia superadora de los riesgos inherentes a la aplicación del Derecho extranjero en determinados sectores, no gozó de una aceptación generalizada, ni encontró especiales proyecciones en la práctica, salvo en ciertos sectores del DIPr de las personas, de la familia y de las sucesiones, donde la aplicación de la lex fori estaba condicionada por la obtención de un determinado resultado. Acaso el ejemplo más típico fueron las disposiciones en materia de divorcio que obligaban al juez a aplicar su propia ley para evitar la aplicación de la ley nacional común de los esposos, normalmente

2 González Campos, J. D., «El paradigma de la norma de conflicto multilateral», Estudios jurídicos en homenaje al profesor Aurelio Menéndez, t. IV, Madrid, Civitas, 1996, pp. 532 y ss.

3 SÁnchez LoRenzo, S., "Postmodernismo y Derecho internacional privado», REDI, vol. XLVI, 1994, pp. 557-585.

4 Bucher, A., "Sur les règles de rattachement à caractère substantiel», Liber amicorum A. Schnitzer, Ginebra, Georg, 1979, pp. 37-55; PAтосcHI, P. M., Règles de rattachement localisatrices et règles de rattachement à caractère substantiel, Ginebra, Georg, 1985; GAUDEMET-TALLON, H., «La utilisation des règles de conflit à caractère substantiel dans les conventions internationales», L'internationalisation du droit: Mélanges en l'honneur de Y. Lousouarn, París, Dalloz, 1994, pp. 181 y ss.

5 Espinar Vicente, J. M., «De lo tradicional y de lo nuevo en el Derecho internacional privado contemporáneo», Cursos de Derecho internacional de Vitoria Gasteiz, 2010, Servicio de Publicaciones, Universidad del País Vasco, 2011, pp. 273-322.

6 Gaudemet-Tallon, H., «Le pluralisme en droit international privé: richesses et faiblesses (Le funambule et l'arc-en-ciel)», Recueil des Cours, t. 312, 2005, pp. 9-488.

7 Audit, B., "Le droit international privé à la fin du XXe siècle: progrès ou recul», Rev. int. $d r$. comp., vol. 50, 1998, pp. 421-448, esp. p. 440.

8 González Campos, J. D., «Les liens entre la compétence judiciaire et la compétence législative en droit international privé», Recueil des Cours, t. 156, 1977, pp. 227 y ss., esp. 237. 
aplicable, cuando prohibía o hacía difícil la disolución del vínculo conyugal ${ }^{9}$. En este caso la solución legeforista se imponía cuando el funcionamiento abstracto de la norma de conflicto corría el peligro de producir resultados poco satisfactorios en la solución del fondo del litigio.

3. El movimiento codificador de finales del siglo $\mathrm{xx}$, tanto interno ${ }^{10} \mathrm{como}$ internacional, también ha aportado instrumentos favorables a la idea de determinar la ley aplicable en función de los elementos del caso concreto ${ }^{11}$. El punto de partida de este nuevo enfoque encontraba una dificultad inherente al propio mecanismo conflictual tradicional por cuanto la designación indirecta de la ley aplicable, dado su mecanicismo y aparente neutralidad ${ }^{12}$, impedía al juez, en principio, tener suficientemente en cuenta los datos propios del caso que deba resolver. No obstante, la incorporación de las nuevas normas de conflicto multilateral, dotadas de un importante elemento flexibilizador, manteniendo su objetivo en pro de la armonía internacional de las soluciones, supuso una ampliación considerable del margen de actuación del juez en el proceso localizador ${ }^{13}$.

La noción de «flexibilización» desborda, sin embargo, la acción creativa del juez abarcando tanto las técnicas que pretenden la consecución de puntos de conexión abiertos, concretados por el juez a la luz de cada supuesto particular, como aquéllas centradas en los denominados «problemas de aplicación de las normas de DIPr», con especial referencia a las cuestiones de adaptación, como, por último, a las acciones en pro de la ampliación del margen de la autonomía de la voluntad de las partes. Y otra importante faceta de la flexibilización es aquella que, sin abandonar el proceso de localización, hace frente a la rigidez de las conexiones de la norma de conflicto, que en determinadas circunstancias pueden designar un ordenamiento jurídico con escasa vinculación con el supuesto produciendo situaciones indeseables.

\subsection{Hacia la aplicación de la «ley más estrechamente vinculada»}

4. El estudio de las modernas legislaciones de DIPr pone de manifiesto la existencia de numerosas normas que habilitan a la autoridad judicial a tomar

\footnotetext{
9 Francescakis, Ph., «Le surprenant article 310 nouveau du Code civil sur le divorce international», Rev. crit. dr. int. pr., 1975, pp. 553 y ss.

10 Véase, con carácter general, VAssilaKaKis, E., Orientations méthodologiques dans les codifications récentes du droit international privé en Europe, París, LGDJ, 1987.

11 Véase VAssilaKaKis, E., «Aspectos relevantes de la codificación reciente del Derecho internacional privado en Europa», Boletín de la Facultad de Derecho (UNED), 1993, núm. 2, pp. 225-248.

12 LoussouarN, Y., «La règle de conflit est-elle une règle neutre?», Travaux Com. fr. dr. int. pr., 19801981, pp. 43 y ss., esp. p. 60.

13 Graulich, P., "La signification actuelle de la règle de conflit», Annales de droit de Liège, 1988, pp. 9-15; GonZÁlez CAmpos, J. D., «Diversification, spécialisation, flexibilisation et matérialisation des règles de droit international privé», Recueil des Cours, vol. 287, 2000, pp. 9-426, esp. pp. 214-308. Este margen de actuación del juez se observa de manera significativa en el Código de DIPr belga de 2004. Véase Watté, N., "Les enjeux de la codification du droit international privé belge», Liber Amicorum Paul Delnoy, Bruselas, Larcier, 2005, pp. 1133 y ss., esp. p. 1140.
} 
en consideración los datos concretos del caso que deben resolver optando, dentro de las leyes eventualmente aplicables, por la ley del país en que se encuentra el centro de gravedad del supuesto litigioso. Se trata de una operación que busca, en último término, la determinación del denominado, según la denominación de P. Lagarde, «principio de proximidad» que es expresivo de la conexión de una relación del tráfico privado externo con el ordenamiento jurídico del país con el que presenta "vínculos más estrechos» ${ }^{14}$.

La flexibilización permitida en la interpretación de la norma de conflicto puede proyectarse también en la propia formulación de la norma, a través del llamado "principio de proximidad», determinando genéricamente la aplicación a una determinada institución o relación jurídica de la «ley más estrechamente vinculada», dejando en manos del juez la valoración de los índices materiales, subjetivos y objetivos del supuesto litigioso para proceder a determinar cuál es el ordenamiento más estrechamente conectado. Con ello los tradicionales mecanismos de localización caracterizados por su generalidad y abstracción quedan reemplazados por criterios concretos y específicos enlazando con las soluciones contenidas en el Restatement (Second) of Conflicts of Laws ${ }^{15}$.

5. La formulación de la most real connection puede venir acompañada de una orientación del legislador, en el sentido de señalar la ley que presumiblemente presente los mayores contactos con el supuesto enjuiciado. Con esta orientación algunas legislaciones de DIPr han recurrido a la denominada «cláusula de excepción» ${ }^{16}$ que se pondrá en marcha cuando aparezca una ley más estrechamente conectada con la relación del tráfico externo que aquélla designada por la norma de conflicto. Se configura así una dualidad reguladora de la localización: de un lado, a través de las normas de conflicto clásicas basadas en puntos de conexión tradicionales y, de otro lado, por medio de una acción institucionalizada que permite al juez aplicar una ley diferente de la designada por la norma de conflicto al poseer la relación jurídica mayor vinculación con ésta. Y esta segunda alternativa puede operar a partir de la existencia de una cláusula de excepción de validez general para todo tipo de supuestos, incluida en una Ley de DIPr, o establecida con carácter derogatorio a las soluciones contenidas en una norma de conflicto específica, supuesto

14 Lagarde, P., «Le principe de proximité dans le droit international privé contemporain», Recueil des Cours, vol. 196, 1986, pp. 9-237, esp. pp. 25 y ss. A ello se refiere expresamente el art. 1.1 de la LDIPr Austria de 1978 cuando determina que «las situaciones que presentan vínculos con el extranjero se regirán, en materia de Derecho privado, por el orden jurídico con el cual existe la relación más estrecha».

15 Symeonides, S. C., "Exception Clauses in American Conflicts Laws», Am. J. Comp. L., vol. 42 (supl.), 1994, pp. 813 y ss.

${ }_{16}$ La paternidad de la expresión se atribuye a G. MARIDAKIS en el informe presentado en la Sesión de Granada del Institut de Droit International de 1956 (MARIDAKIs, G., "Rapport définitif sur le renvoi en droit international privé», Annuaire de l'IDI, vol. 47-II, 1957, pp. 5 y ss., esp. p. 53). Para el autor griego, la misión atribuida a la norma de conflicto de hacer justicia fracasaría si la situación jurídica estuviese más estrechamente conectada a la ley de un Estado distinto del localizado por la misma; por eso estaba justificada la excepción en ciertos supuestos en que circunstancias particulares aconsejasen la aplicación de otras leyes más apropiadas. La propuesta no encontró, sin embargo, un clima favorable entre los colegas del Instituto, siendo objeto más bien de duras críticas (ibid., pp. 57 y ss.). 
que es particularmente evidente en el ámbito de la contratación, pero que observa cada vez mayor extensión, penetrando incluso en el Derecho de familia y en el Derecho sucesorio. Ambas posibilidades, general o especial, presentan en común la facultad atributiva o correctora del juez para determinar la ley aplicable ${ }^{17}$, lo que implica, en todo caso, conferir al juez un margen de apreciación importante y, con ello, la confluencia con las doctrinas gestadas en el círculo norteamericano se hace patente.

$\mathrm{Al}$ mantener la exigencia de un vínculo suficiente con un sistema legal determinado, consustancial al DIPr ${ }^{18}$, esta posición aboga por una alternativa fundamental: aplicar la ley del país con el cual el caso está más estrechamente vinculado, o elegir la ley cuya aplicación conduce al resultado material más apropiado en función de los elementos del caso. Dicho de otro modo, la determinación de la ley aplicable por la localización del caso concreto cede ante la determinación de la ley aplicable en función de su contenido material. Como puede observarse, la cláusula de excepción opera en el propio mecanismo conflictual únicamente en ciertos supuestos y nunca con un efecto derogatorio extensivo.

6. Para alcanzar un elevado nivel de justicia, los legisladores internos o internacionales procuran introducir en la norma de conflicto puntos de conexión con un alto grado de previsibilidad, aunque en ocasiones estos últimos por su excesiva rigidez no establecen una ley idónea para regular la relación jurídica o se remite a la ley de un país con una escasa o nula vinculación con dicha relación. La cuestión estriba entonces en el margen de actuación del juez ${ }^{19}$ para corregir ese desequilibrio y con este propósito, como se ha apuntado $^{20}$, algunos sistemas establecen un mecanismo de excepción que puede venir determinado por una cláusula de carácter general o por cláusulas específicas referidas a concretas situaciones del tráfico privado externo ${ }^{21}$. Dicha técnica parte de la insuficiencia de la norma de conflicto del foro para dar una respuesta adecuada a la situación privada internacional incorporando un mecanismo corrector $^{22}$ que vincula el asunto a la ley más adecuada, ignorando el mandato incorporado en la norma de conflicto y dosificando con ello su

17 Véase Picone, P., «Les méthodes de coordination entre ordres juridiques en Droit international privé Cours général de droit international privé», Recueil des Cours, t. 276, 1999, p. 80.

18 ANCEL, B., «Regards critiques sur l'érosion du paradigme conflictuel», Cursos de Derecho internacional de Vitoria-Gasteiz. 2005, Universidad del País Vasco, pp. 347-415, esp. p. 355.

19 Desde una perspectiva histórica resulta de interés el estudio de RÉMY, Ph., «La part faite au juge», Pouvoirs, revue française d'études constitutionnelles et politiques, 2003, núm. 107, Le Code civil, pp. 22-36, http://www.revue-pouvoirs.fr/La-part-faite-au-juge.html.

20 Véase, supra, núm. 3.

21 Véase KoKkini-Iatridou, D., «Les clauses d'exception en matière de conflits de lois et de conflits de juridictions", Les clauses d'exception en matière de conflits de lois et de conflits de juridictions —ou le principe de proximité-. XIV Congrès international du droit comparé, Athènes 1994, Rapports généraux, Dordrech, Niihoff, 1994, pp. 3 y ss.; RÉmY CORLAY, P., «Mise en oeuvre et régime procédural de la clause d'exception dans les conflits de lois», Rev. crit. dr. int. pr., 2003, pp. 37-76; LAGARDE, P., «Le principe de proximité...», op. cit., nota 14, pp. 97-126; VISCHER, F., "General Course on Private International Law», Recueil des Cours, t. 232, 1992, pp. 9-255, esp. pp. 106-112.

${ }^{22}$ Así, en materia contractual, véase ANCEL, M. E., La prestation caractéristique du contrat, París, Economica, 2002, p. 337, y MarTínez LunA, W. F., «El artículo 4.3 del Reglamento Roma I. Una ver- 
evidente grado de abstracción. Su finalidad es, pues, corregir una situación injusta determinada por la remisión contenida en la norma en aras de la justicia material y no una materialización de la solución. Se erige así como un complemento a la tradicional función localizadora de la norma de conflicto.

\section{CLÁUSULAS DE EXCEPCIÓN DE ALCANCE GENERAL}

\subsection{Manifestaciones}

7. Las cláusulas de excepción o cláusulas de escape, constituyen una manifestación fidedigna del principio de proximidad. Su pretensión de localizar el Derecho que tenga los vínculos más estrechos con la situación del tráfico externo $^{23}$, obedece a un principio de «justicia conflictual» ${ }^{24}$, expresión que debe utilizarse con toda reserva al margen de su utilidad pedagógica, pues los límites entre esta última y la justicia material se han difuminado gradualmente, como se demuestra por el número cada vez mayor de mecanismos y métodos de regulación de las relaciones privadas internacionales emergentes. Dicho en otros términos: la corrección de la norma general no puede cimentarse en la consecución de un resultado material más ajustado o convincente, sino en la mayor proximidad o vinculación del supuesto con una de las leyes en presencia, independientemente de su resultado material ${ }^{25}$.

El modelo de cláusula de excepción de alcance general, cuyos antecedentes doctrinales se han señalado ${ }^{26}$, figura en buena parte de las reglamentaciones, internas e internacionales del DIPr y, aunque dista mucho de constituir un principio generalmente aceptado, es una manifestación importante del reparto de responsabilidades entre el legislador y el juez en la solución a las cuestiones del tráfico privado externo ${ }^{27}$. Dejando a un lado el contenido del art. 1 de la LDIPr Austria de 1978, cuyo valor como antecedente de la cláusula de excepción resulta controvertido ${ }^{28}$ por constituir más bien una cláusula de escape que sustituye la función de una norma de conflicto, resulta un referente obligado de las posibilidades correctoras del juez en el proceso de localización el art. 15 de la LDIPr Suiza, según el cual:

\footnotetext{
dadera cláusula de excepción», REEI, diciembre 2012, núm. 24, file://C:/Users/user/Downloads/Nota_ MARTINEZ_WFernando.pdf.

23 Knoepfler, F., «Utilité et dangers d'une clause d'exception en droit international privé», Hommage à Raymond Jeanprêtre, Neuchâtel, Ides et calendes, 1982, pp. 113 y ss., esp. p. 118.

${ }^{24}$ Véase, por todos, Kegel, G., "The Crisis of Conflicts of Laws», Recueil des Cours, t. 112, 1964, pp. 91 y ss.; VitTA, E., "Cours général de droit international privé», Recueil des Cours, t. 162, 1979, pp. 37 y ss.

25 Véase Fernández Rozas, J. C., «Orientaciones del Derecho internacional privado en el umbral del siglo XXI», Revista Mexicana de Derecho Internacional Privado, 2000, núm. 9, pp. 7-32.

26 Véase, supra, nota 16.

27 Rigaux, F., "La méthode des conflits de lois dans les codifications et projets de codification de la dernière décennie», Rev. crit. dr. int. priv., 1985, pp. 1 y ss., p. 4.

28 VASSILAKAKIS, E., «Aspectos relevantes de la codificación...», op. cit., nota 11, p. 241. El referido precepto austriaco no cumple función correctora alguna limitándose a incorporar una directriz dirigida al juez.
} 
"Le droit désigné par la présente loi n'est exceptionnellement pas applicable si, au regard de l'ensemble des circonstances, il est manifeste que la cause n'a qu'un lien très lâche avec ce droit et qu'elle se trouve dans une relation beaucoup plus étroite avec un autre droit.

2. Cette disposition n'est pas applicable en cas d'élection de droit».

Dicho precepto no puede comprenderse sin una vinculación directa con el art. 1.2, en relación con los arts. 2 y 4, del Código Civil de este país, que a principios del siglo xx supuso una gran novedad en el entorno comparado por otorgar un importante papel creador al juez ${ }^{29}$. De su redacción se desprende que incluye una doble consideración. De un lado, que el asunto en cuestión tenga un vínculo muy débil con el Derecho designado por la norma de conflicto y, de otro lado, que cuente con un vínculo más estrecho con otro ordenamiento; de esta suerte el Derecho designado por la norma de conflicto únicamente puede ser excluido cuando el supuesto no esté fuertemente vinculado a tal ordenamiento; más aún, se exige una desvinculación clara con el Derecho designado $^{30}$.

Con una influencia inequívoca del modelo suizo, varias modernas leyes de DIPr han incorporado una norma de similar tenor al texto transcrito. Es el caso del art. 3.082 del Código Civil de Quebec de 1991 ${ }^{31}$; del art. 2 de la LDPr de Eslovenia de 1999²; del art. 1.11.3 del Código Civil de Lituania de 2000³3; del art. 19 del Código de DIPr de Bélgica de 2004 ${ }^{34}$; del art. 3 de la LDIPr de

29 De acuerdo con esta disposición: «A défaut d'une disposition légale applicable, le juge prononce selon le droit coutumier et, à défaut d'une coutume, selon les règles qu'il établirait s'il avait à faire acte de législateur». Véase Lucien-Brun, P., Le Rôle et les Pouvoirs DU JUGE dans le Code civil suisse, Grenoble, Imprimerie Saint-Brune, 1920, https://archive.org/stream/leroleetlespouvo00luci/leroleetlespouvo00luci_ djvu.txt. Desde una perspectiva más actual, véase Papaefthymiou, S., «Mind the Gap. Dits et non-dits sur les pouvoirs du juge suisse», en CAYLA, O. y REnOuXZaGAME, M.-F., L'office du juge: part de souveraineté ou puissance nulle?, París, LGDJ, 2001, pp. 195-226.

30 Bucher, A., "La clause d'exception dans le contexte de la partie générale de la LDIP», La loi fédérale de droit international privé: vingt ans après. Actes de la 21e Journée de droit international privé du 20 mars 2009 à Lausanne, Ginebra, Schulthess, 2009, pp. 59 y ss.

31 Art. 3082: "À titre exceptionnel, la loi désignée par le présent livre n'est pas applicable si, compte tenu de l'ensemble des circonstances, il est manifeste que la situation n'a qu'un lien éloigné avec cette loi et qu'elle se trouve en relation beaucoup plus étroite avec la loi d'un autre État. La présente disposition n'est pas applicable lorsque la loi est désignée dans un acte juridique».

32 Art. 2.1: "The law that provisions of this Act instruct to use shall exceptionally not be used when, in view of all circumstances of the case, it is clear that the relation with that law is not the most important one and that there is an essentially closer link to some other law. / 2. This provision shall not apply when the law is chosen by the parties", http://www.uaipit.com/files/documentos/0000004965_THE_PRIVATE_ INTERNATIONAL_LAW_AND_PROCEDURE_ACT_1999_07_13.pdf.

33 "3. In accordance with this Code, the applicable foreign law may not be given effect where, in the light of all attendant circumstances of the case, it becomes evident that the foreign law concerned is clearly not pertinent to the case or its part, with the case in question being more closely connected with the law of another state. This provision shall not apply where the applicable law is determined by the agreement of the parties", http://www.wipo.int/edocs/lexdocs/laws/en/lt/lt073en.pdf.

34 Art. 19: "Clause d'exception. § 1er. Le droit désigné par la présente loi n'est exceptionnellement pas applicable lorsqu'il apparaît manifestement qu'en raison de l'ensemble des circonstances, la situation n'a qu'un lien très faible avec l'Etat dont le droit est désigné, alors qu'elle présente des liens très étroits avec un autre Etat. Dans ce cas, il est fait application du droit de cet autre Etat. / Lors de l'application de l'alinéa 1er, il est tenu compte notamment: —du besoin de prévisibilité du droit applicable, et - de la circonstance que la relation en cause a été établie régulièrement selon les règles de droit international privé des Etats 
Macedonia 2007, que reproduce el art. 15 de la LDIPr Suiza ${ }^{35}$ o, más recientemente, del art. 2.597 del Código Civil de Argentina ${ }^{36}$.

La apuntada introducción del modelo en Bélgica se realizó no sin un importante debate, vinculado a la inserción del foro de necesidad en el art. 11 del Código. Se consideraba que no era otra cosa que mimetismo hacia una institución que se había puesto de moda ${ }^{37}$, reñido con la meticulosidad practicada en un proceso de la elaboración de las normas de conflicto caracterizado por la búsqueda de la proximidad. Incluso el propio Consejo de Estado, valorando el texto del proyecto, mucho más liberal que el del actual art. 19, insistía en que la cláusula de excepción diseñada no sólo socavaba el esfuerzo realizado por los redactores de las normas de conflicto, sino que ponía en peligro la utilidad del Código en su conjunto ${ }^{38}$.

\subsection{Caracterización}

8. A diferencia de las cláusulas correctoras de la localización, esto es, los denominados problemas generales de aplicación de la norma de conflicto (orden público, reenvío, adaptación...), cuya función es descartar la aplicación del Derecho extranjero ${ }^{39}$, en las cláusulas de excepción la corrección se realiza a través de una técnica que tiene un carácter «escapatorio» o «de exclusión» praeter legem. A partir de ella el juez cuenta con una potestad «institucionalizada», al estar habilitado por el legislador, para determinar la ley aplicable ${ }^{40}$, siempre que la situación presente inequívocamente "vínculos más estrechos» con otro orden jurídico del designado por la norma de conflicto. Dicha potestad se ejerce en dos etapas de carácter sucesivo, en la primera, el juez deberá verificar la idoneidad de la norma de conflicto en orden a la inclusión de vínculos suficientes entre el supuesto y el Derecho designado; en la segunda,

avec lesquels cette relation présentait des liens au moment de son établissement. / § 2. Le § 1er n'est pas applicable en cas de choix du droit applicable par les parties conformément aux dispositions de la présente loi, ou lorsque la désignation du droit applicable repose sur le contenu de celui-ci».

${ }_{35}$ Deskoski, T., «The New Macedonian Private International Law Act of 2007», Yearb. Pr. Int'l L., vol. 10, 2008, pp. 441-458, esp. p. 443.

36 Art. 2.597: «Cláusula de excepción. Excepcionalmente, el derecho designado por una norma de conflicto no debe ser aplicado cuando, en razón del conjunto de las circunstancias de hecho del caso, resulta manifiesto que la situación tiene lazos poco relevantes con ese derecho y, en cambio, presenta vínculos muy estrechos con el derecho de otro Estado, cuya aplicación resulta previsible y bajo cuyas reglas la relación se ha establecido válidamente. / Esta disposición no es aplicable cuando las partes han elegido el derecho para el caso».

37 BARNICH, L., «La clause d'exception dans la proposition de loi portant le Code de droit international privé», Mélanges John Kirkpatrick, Bruselas, Bruylant, 2004, pp. 59-72, esp. p. 72.

38 Wautelet, P., «Le nouveau droit international privé belge: Conflits de lois», Journal des tribunaux, 2005, núm. 6173, p. 180, http://www.dipulb.be/fileadmin/user_files/JT_Boularbah_CODIP.pdf.

39 Pamboukis, Ph., «Les clauses d'exception en matière de conflits de lois et de conflits de juridiction", en KoKkini-Iatridou, D. (dir.), Les Clauses d'Exception En Matière De Conflits De Lois et De Conflits De Juridictions - Ou le Principe De Proximité: Exception Clauses in Conflicts of Laws and Conflicts of Jurisdictions - or the Principle of Proximity, Deventer, Springer, 1994, pp. 221 y ss.

${ }^{40}$ Véase GonzÁlez Campos, J. D., «Diversification, spécialisation, flexibilisation...», op. cit., nota 13, p. 218 . 
una vez comprobada la inidoneidad de la localización, procederá a corregir esta última aplicando el ordenamiento jurídico más próximo.

Es obvio que la apreciación de esta noción puede dar lugar a numerosas situaciones de incertidumbre ${ }^{41}$, pero en su obligado juicio de valor el juez debe atender a consideraciones totalmente independientes del resultado obtenido por la ley inicialmente designada; un juicio de valor que se superpone al punto de conexión inicialmente fijado por el legislador, cuya pretensión, al permitir la corrección, es que se aplique el Derecho que presenta mayores vínculos con el supuesto regulado y, de ahí, la presencia de la cláusula de excepción, para resolver el supuesto con mayor justicia. El problema es que las cláusulas de excepción de alcance general que estamos examinando no establecen unos criterios definidos que permitan llevar al convencimiento del juez de las razones que justifican la derogación del mandato contenido en la norma de conflicto o que posibiliten medir si el vínculo es débil o fuerte. Además, no siempre la ley que presenta los vínculos más estrechos con el supuesto es la más apropiada.

Nos hallamos en presencia de un correctivo a la localización cuya finalidad no es entorpecer sino, por el contrario, mejorar el mandato de la norma de conflicto eliminando la rigidez que puede caracterizarla, bien es verdad que en detrimento del valor «seguridad jurídica», en el sentido de aportar menor certidumbre y menor previsibilidad. Es más, la flexibilidad que la cláusula de excepción añade muestra de una especial preferencia hacia aquellas normas de conflicto que carezcan de tal virtualidad.

Partiendo del carácter imperativo de la norma de conflicto, la cláusula no tiene un ámbito de aplicación de carácter universal sino que opera, y en esto existe un claro consenso doctrinal, con carácter excepcional ${ }^{42}$, como un instrumento meramente corrector del sistema, cuando el proceso de localización produzca como resultado una solución inadecuada o arbitraria ${ }^{43}$ y siempre que las circunstancias así lo exijan. Por eso se ha propuesto que, para evitar su empleo excesivo en ciertos sectores como el de las obligaciones extracontractuales, podría ser necesaria una mayoría calificada o incluso la unanimidad de la decisión judicial que las adoptara o transferir esta última a un tribunal superior más especializado o, incluso, al TJUE.

9. Su aplicación posee una evidente nota de excepcionalidad y su interpretación un carácter restrictivo ${ }^{44}$, con lo cual la cláusula de excepción no

41 Fentiman, R., "The Significance of Close Connection», en Ahern, J. y Binchy, W. (eds.), The Rome II Regulation on the Law Applicable to Non-Contractual Obligations, Leiden, Nijhoff, 2009, pp. 85112, esp. p. 92.

42 Schäfer, H.-B. y Lanterman, K., «Choice of Law form a Economic Perspective», en Basedow, J. y Kono, T., An Economic Analysis of Private International Law, Tubinga, Mohr Siebeck, 2006, pp. 87120, esp. p. 92.

43 Refiriéndose al art. 15 de la LDIPr de Suiza, la Sentencia del Tribunal Federal de 27 de enero de 1992 (ATF 118 II 79, 82, asunto, W. c. Dame W) ha puesto de relieve que la cláusula de excepción en sentido estricto únicamente puede ser aplicada en caso de necesidad.

44 Sentencia de la Cour civil suiza de 7 de abril de 1995 (Dame P. B. c. P. B.) ATF 121 III 247. 
tiene vocación de convertirse en una regla general que sustituya al mecanismo de la norma de conflicto multilateral. La orientación de esta última, sobre todo en las modernas codificaciones, busca por sí misma la realización de la proximidad y las más de las veces lo consigue, pero pueden aparecer supuestos en los que el legislador ha errado en su previsión y ese es precisamente el momento donde la cláusula de excepción despliega su eficacia con el objetivo de restablecer la certidumbre en la elección del Derecho aplicable $^{45}$.

Evidentemente, la extensión del margen de apreciación al juez puede repercutir en el grado de previsibilidad inherente a la norma de conflicto afectando directamente a la seguridad jurídica, de suerte que la flexibilidad de las decisión del juez con apoyo en la cláusula de excepción es susceptible de aumentar el grado de imprevisibilidad de su decisión ${ }^{46}$, aunque también lo es de posibilitar la respuesta adecuada del juez teniendo en cuenta los intereses de las partes ${ }^{47}$. Bien entendido que la previsibilidad de las normas de conflicto bilaterales está en función de cómo estén redactadas las cláusulas de excepción, tanto de carácter general como particular, y de la corrección en la aplicación que se efectúe de las mismas por parte del juez ${ }^{48}$.

10. Como puede observarse, estamos ante una técnica que toma como referente principal el poder moderador del juez a la hora de analizar la referida vinculación, que puede contribuir a la realización de la justicia material, aplicando la ley que presenta vínculos más estrechos con la relación ${ }^{49}$, y en tal sentido constituir una herramienta fundamental de un sistema de DIPr ${ }^{50}$. El volumen de flexibilidad que la cláusula de excepción incorpora es esencial para corregir la rigidez de la norma de conflicto cuando emplea conexiones tales como la nacionalidad, el lugar donde se ha producido el hecho ilícito, o el lugar de situación del inmueble. Sin embargo, ello no acontece cuando las soluciones están determinadas por el domicilio o por la residencia habitual, que permiten al juzgador un mayor margen de interpretación, cuestión que debe considerarse en un contexto más amplio, incluyendo el contenido de las soluciones de justicia que suministran los jueces en un determinado sistema

45 Lagarde, P., «Le príncipe de proximité...», op. cit., nota 14, p. 116.

46 VAssilaKaKIs, E., «Aspectos relevantes de la codificación...», op. cit., nota 11, p. 247.

47 Así lo ha entendido la jurisprudencia suiza en aplicación del art. 15 de la LDIPr. Según el Tribunal federal: "Cette disposition n'a toutefois pas été conçue pour réprimer les détournements de la loi suisse, mais pour permettre au juge de trouver, dans l'intérêt des parties, la solution la plus adéquate dans une cause donnée (Message, p. 300). Avant l'entrée en vigueur de la LDIP, cette exception au rattachement normal résultait de la jurisprudence du Tribunal fédéral, qui l'appliquait surtout en matière de contrats et toujours dans l'intérêt des parties» (ATF 117 II 494 ss., 501).

48 Audit, B., «Le droit international privé en quête d'universalité», Recueil des Cours, t. 305, 2003, pp. 9-488, esp. p. 336 .

49 Dubler, C., Les clauses d'exception en droit international privé, Ginebra, Etudes suisses de droit international privé, 1983, p. 28.

50 VRellis, S., "La justice "matérielle" dans la codification du droit international privé», en Borrás, A., Bucher, A., Struycken, T. y Verwilghen, M. (eds.), E Pluribus Unum. Liber amicorum Georges A.L. Droz. On the Progressive Unification of Private International Law - Sur l'unification progressive du droit international privé, La Haya-Boston-Londres, Nijhoff Publishers, 1996, pp. 541-561. 
jurídico estatal, dentro de la ampliación de sus facultades de apreciación que es consustancial a las codificaciones contemporáneas.

En la actualidad un número no desdeñable de disposiciones estipulan, en su ámbito de aplicación, la libertad del juez en la elección de la ley aplicable. Ahora bien, la puesta en marcha de la cláusula por el juez debe estar desprovista de cualquier vestigio de arbitrariedad, pues únicamente puede operar en una hipótesis concreta al estar comprendida su aplicación dentro de los estrictos "vínculos más estrechos», a partir de una operación de comparación entre la proximidad del supuesto con la ley designada por la norma de conflicto y la vinculación de éste con el Derecho de otro país. Ello debería frenar cualquier veleidad legeforista por parte del juez en el sentido de recurrir a su propia ley so pretexto de que dichos vínculos más estrechos conducen inexorablemente a la aplicación de la lex fori. La experiencia demostrada en el marco de aplicación de los tradicionales correctivos funcionales de la norma de conflicto advierten claramente que esta tendencia legeforista no es una mera hipótesis. Precisamente para evitar una tendencia abusiva del juez en tal sentido, que es inevitable aunque contraríe el espíritu de la institución que estamos estudiando ${ }^{51}$, algunas modernas leyes de DIPr han preferido excluir la cláusula de excepción de carácter general como la italiana o la dominicana ${ }^{52}$ no recibiendo las que han optado por ella un apoyo unánime ${ }^{53}$.

11. En la formulación contenida en los modernos textos de DIPr donde figura, la cláusula de excepción está desprovista, en principio, de cualquier connotación material o indiciaria hacia la consecución de determinados valores, protección de concretos intereses u obtención de resultados precisos, por más que la intervención del juez a la hora de materializar el concepto de contenido variable de "conexiones más estrechas» pueda derivar en lo contrario $^{54}$. Ahora bien, el empleo de la cláusula no es unívoco, admitiendo dos modalidades de contenido diverso: activa, si el resultado de su aplicación conduce a la aplicación de la ley del foro cuando la norma de conflicto remite al Derecho extranjero, y pasiva, cuando en esta misma hipótesis se descarte su aplicación con el objetivo de someter la relación al Derecho del foro ${ }^{55}$.

51 BARNICH, L., «La clause d'exception dans la proposition de loi portant le Code de droit international privé», Mélanges John Kirkpatrick, Bruselas, Bruylant, 2004, pp. 70 y ss., esp. p. 72.

52 Es el caso de la LDIPr de la República Dominicana de 2014. Como señala J. C. FERnÁNDEz RozAs, «Au moment d'introduire pareille clause dans le système dominicain, la commission a été retenue par deux facteurs: d'abord, cette institution n'est pas l'objet d'un accueil généralisé en droit international privé comparé et, ensuite, elle ne peut en toute hypothèse être mise en cuvre par les interprètes les mieux entrainés qu'avec la plus grande précaution» (véase FERNÁNDEz RozAS, J. C., «Le nouveau droit international privé de la République dominicaine», Rev. crit. dr. int. priv., 2015, pp. 303 y ss., esp. p. 321).

53 Véanse en relación con el art. 2.597 CC argentino los comentarios críticos de Menicocci, A. A., Codificación de Derecho internacional privado, con especial referencia a la parte general y a la regulación patrimonial en el proyecto de Código Civil y comercial de la Nación, Asociación Argentina de Derecho Internacional, http://www.aadi.org.ar/index.php?acc $=5 \& o p c=2$

54 Álvarez GonzÁlez, S., "Objeto del Derecho internacional privado y especialización normativa», Anuario de Derecho Civil, vol. 46, 1993, núm. 3, pp. 1109-1051, esp. p. 1131.

55 Dubler, C., Les clauses d'exception..., op. cit., nota 49, p. 211. 
Para la puesta en marcha de la cláusula de excepción deberá acreditarse plenamente que la situación presenta un vínculo más estrecho con otro Derecho del designado por la norma de conflicto, lo que requiere una explicación fehaciente de la inadecuación de esta última evidenciando que dicho Derecho está desinteresado en la referida situación. Se parte, pues, de la existencia de una norma de conflicto plenamente operativa, cuyo punto de conexión designa un Derecho determinado y cuya aplicación se soslaya por la actuación del juez. En tal sentido la cláusula carece de sentido cuando la norma de conflicto contiene como conexión única el vínculo más estrecho. Ello requiere que el mecanismo de localización incluido en la norma de conflicto pueda aislarse tanto en el espacio como en el tiempo ${ }^{56}$.

\subsection{Consideraciones críticas}

12. La recepción de la cláusula de excepción de alcance general no ha sido pacífica, sobre todo en la doctrina francesa ${ }^{57}$, incluso en el interior de un sistema donde contaba con una cierta justificación estructural como el suizo; y la misma suerte aconteció con la iniciativa belga ${ }^{58}$. Al margen de la ya apuntada afectación al principio de seguridad jurídica ${ }^{59}$, desde una perspectiva formalista la mayor objeción a la cláusula es que las normas jurídicas deben llevar incorporado un necesario componente de certidumbre al que los particulares pueden acogerse y si se permite al juez alterar el mandato que contienen se pone en peligro la propia coherencia del sistema de $\mathrm{DIPr}^{60}$.

No puede desdeñarse la existencia de una tendencia natural del juez para eliminar el factor de conexión cada vez que otra solución le parece más ajustada ${ }^{61}$; además se corre con ella el peligro de conferir al juez un instrumento tendente a la aplicación de la ley del foro o para otras finalidades de carácter

56 Véase Remy-Corlay, P., «Mise en œuvre et régime procédural de la clause d'exception dans les conflits de lois», Rev. crit. dr. int. priv., 2003, pp. 37-76, esp. p. 41.

57 En Francia, por ejemplo, tras la disertación de A. E. vON OvERBEcK en el Comité francés de DIPr arreciaron las críticas por parte de destacados especialistas de la doctrina francesa. Véase vON OvERBECK, A. E., «Quelques solutions générales du projet suisse de loi sur le droit international privé et premières réactions à leur égard», Travaux Com. fr. dr. int. pr., 1980-1981, pp. 79 y ss.

58 Con ocasión de la elaboración del Código de DIPr de Bélgica el Consejo de Estado de este país consideró que su inclusión comprometía la utilidad del propio proyecto. Véase WAUTELET, P., «Le code de droit international privé ou l'avènement d'un droit international privé "flexible" ", Revue de la Faculté de Droit de l'Université de Liège, 2006, pp. 347-364, nota 16.

59 Fiorini, A., «The Codification of Private International Law: the Belgian Experience», Int'l Comp. L. Q., vol. 54, 2005, núm. 2, pp. 499-519, esp. pp. 515-517.

60 Véanse las observaciones de M. Huet a la disertación de Verwilghen, M., "Vers un code belge de droit international privé. Présentation de l'avant projet de loi portant Code de droit international privé», Travaux Com. fr. dr. int. pr., 1998-1999, pp. 123 y ss., esp. p. 159. En España ToMÁs ORTIZ DE LA TORRE, J. A., «El Reglamento Europeo sobre sucesiones y testamentos: breves reflexiones (y algunas digresiones) desde una perspectiva española», Revista Jurídica de Asturias, 2014, núm. 37, pp. 97-127, esp. pp. 122-124.

${ }_{61}$ Véase MAYER, P., «Le phénomène de la coordination des ordres juridiques étatiques en droit privé. Cours général de droit international privé», Recueil des Cours, t. 327, 2007, p. 170. 
torticero, o utilizar la cláusula como un instrumento para la aplicación del Derecho del foro.

13. Frente a estos planteamientos críticos, se insiste en que la introducción de cláusulas de excepción de carácter general en un sistema de DIPr:

i) No supone el desmantelamiento del mecanismo conflictual, que sigue constituyendo la estructura maestra y conservando su validez; sobre todo si se presume, como en el caso suizo o en el belga, que los redactores del cuerpo legal que las incluye han estudiado en profundidad el alcance de la localización incorporando un vínculo estrecho entre la relación regulada y el ordenamiento jurídico aplicable. Además, su carácter complementario tiene por objeto corregir aquellos supuestos en los cuales el legislador no ha podido localizar el centro de los intereses de la relación jurídica regulada.

ii) Tiene un alcance limitado pues los nuevos textos de DIPr que las contemplan incorporan otros instrumentos que confieren un margen de apreciación al intérprete, en ocasiones de gran amplitud, por lo que no parece que la introducción de una cláusula de exclusión de carácter general esté reñida con el espíritu de dichos instrumentos.

iii) Responde a una circunstancia realista en el sentido de que un sistema estatal de DIPr, por perfecto que sea, no es capaz de elaborar normas de conflicto de carácter multilateral susceptibles de solucionar de manera satisfactoria la localización del Derecho extranjero.

iv) Está sometida a una serie de reservas, en concreto la cláusula de excepción no operará en caso de que la norma de conflicto incorpore conexiones de carácter subsidiario y tampoco se pondrá en marcha cuando las partes hayan elegido previamente el Derecho aplicable. Y ello enlaza con otra nota característica de la reciente codificación del DIPr cual es la de la ampliación generalizada del ámbito de la autonomía de la voluntad, tradicionalmente reservada al sector de la contratación a un bien número de materias. En efecto, en los últimos tiempos se considera que son las partes los mejores intérpretes de sus intereses en el proceso de localización y esta idea cuenta con una importante proyección en numerosas relaciones del tráfico externo como el régimen económico matrimonial, el divorcio y la separación, las obligaciones alimenticias, las obligaciones extracontractuales o el trust. Dicha tendencia restringe de manera considerable el ámbito de las cláusulas de excepción tanto de carácter general como sectorial ${ }^{62}$.

62 Inter alia, CARLIER, J.-Y., Autonomie de la volonté et statut personnel, Bruselas, Bruylant, 1992; Gannagé, P., "La pénétration de l'autonomie de la volonté dans le droit international privé de la famille», Rev. crit. dr. int. pr., 1992, pp. 425-454; vON OvERBECK, A. E., "L'irrésistible extension de l'autonomie en droit international privé», Nouveaux itinéraires en droit. Hommage à François Rigaux, Bruselas, Bruylant, 1993, pp. 619 y ss.; ÁlvArez GonzÁlez, S., «Breves notas sobre la autonomía de la voluntad en Derecho internacional privado", Soberanía del Estado y Derecho Internacional. Homenaje al Profesor Carrillo Salcedo, vol. I, Sevilla, Universidad de Sevilla, 2005, pp. 137 ss.; KoHLER, C., «L'autonomie de la volonté en droit international privé: un principe universel. Entre libéralisme et étatisme», Recueil des Cours, t. 359, 2013, pp. 285-478. 


\section{CLÁUSULAS DE EXCEPCIÓN Y ESPECIALIZACIÓN NORMATIVA}

\subsection{Vinculación al mecanismo de localización}

14. Si las cláusulas de excepción de aplicación general han suscitado y siguen suscitando reservas, cuando se han proyectado a situaciones concretas han demostrado su operatividad, de ahí su acogida favorable como importante elemento corrector. Por eso, la cláusula de excepción a la ley normalmente aplicable resulta un mecanismo óptimo de especialización en razón del grado de heterogeneidad; diversificación que va más allá incluso de la que reflejan las normas a las que eventualmente excepciona ${ }^{63}$.

Ahora bien, la especialización de las cláusulas de excepción no supone que su función sea similar en todos los casos, pues pueden funcionar o bien en tanto que normas reguladoras de situaciones concretas, o bien, más propiamente, como instrumentos correctores. Todo apunta hacia la necesidad de tomar en consideración elementos de carácter material y de justicia y no hacia actuaciones de carácter oportunista y coyuntural. Por ejemplo, en el ámbito patrimonial, las conexiones o las presunciones suelen conducir a la ley del mercado afectado, a la que mejor proteja la seguridad del tráfico internacional, o a la que genere menores costes de transacción, a la más eficiente, etc. Y, correlativamente, en el ámbito no patrimonial, la conexión general debe o suele reflejar el medio social en que viven los cónyuges, la familia o el individuo; por último, en materia de sucesiones, se trata de combinar ambos aspectos, personal e individual ${ }^{64}$.

15. Debe insistirse en que el ámbito de actuación de la cláusula de excepción de carácter especial opera en el propio proceso de localización y por tanto no puede utilizarse para otros menesteres como el de colmar una eventual laguna o resolver un problema de interpretación. Se habla en estos últimos casos de cláusulas de escape sustitutorias de las normas de conflicto, o cláusulas de excepción cerradas, que también acuden a la ley que presente los vínculos más estrechos con la situación privada internacional y que indudablemente resultan de gran utilidad, cumpliendo funciones diversas tales como resolver la imposibilidad material de aplicación del Derecho extranjero $^{65}$, como mecanismo de designación de la ley aplicable en defecto de los puntos de conexión, o actuando en ocasiones como cláusula de cierre ante la imposibilidad de aplicar otras conexiones al respecto.

De estas últimas hipótesis resultan ilustrativos cuatro ejemplos, entre otros muchos que pudieran aportarse. En primer lugar, el art. 48 de la LDIPr suiza que, tras señalar en su párr. 1 que la ley aplicable a los efectos del matrimonio será aquélla donde los esposos tengan su domicilio, incorpora en

\footnotetext{
63 Álvarez GonzÁlez, S., «Objeto del Derecho internacional privado...», op. cit., nota 54, p. 1134.

${ }^{64}$ Véase Fernández Rozas, J. C., "Orientaciones del Derecho internacional privado...», op. cit., nota 25, núm. 17.

${ }^{65}$ Véase el art. 10.1 de la LDIPr polaca de 2011.
} 
el párr. 2 la regla de los vínculos más estrechos para los supuestos en que no exista domicilio común. En segundo lugar, en el mismo cuerpo legal, la regla se pone en marcha en ausencia de designación de ley aplicable (art. 67) a las relaciones personales o patrimoniales en el matrimonio (art. 51.2) o en materia de adopción (art. 57.2) ${ }^{66}$. En tercer lugar, resulta obligada la referencia al art. 4.4 del Reglamento (CE) núm. 593/2008, de 17 de junio, sobre la ley aplicable a las obligaciones contractuales (RR I): «Cuando la ley aplicable no pueda determinarse con arreglo a los apartados 1 o 2, el contrato se regirá por la ley del país con el que presente los vínculos más estrechos»; asimismo, debemos referirnos al art. 9 del la Convención de México de 1994 sobre ley aplicable a los contratos internacionales que determina que «si las partes no hubieran elegido el Derecho aplicable, o si su elección resultara ineficaz, el contrato se regirá por el Derecho del Estado con el cual tenga los vínculos más estrechos», estableciendo en el párrafo siguiente los criterios que debe adoptar el juez para determinar dichos vínculos. Un último ejemplo lo ofrece el art. 62 de la LDIPr de la República Dominicana que, tras fijar que los contratos de trabajo se rigen por la ley del país donde habitualmente se realiza la prestación laboral, dispone que si ésta ley no pudiera determinarse se estará a «la ley del país que presente los vínculos más estrechos».

16. Siguiendo el hilo conductor trazado en el inicio del presente estudio, nos detendremos en el estudio de las cláusulas de excepción strictu sen$s u$, también denominadas cláusulas de excepción abiertas, cuya función es «reenviar al orden jurídico que presenta los vínculos más estrechos con el supuesto concreto, sin establecer indicación alguna en torno a esos vínculos, que deben ser determinados por el juez» ${ }^{67}$. Esto es, unas cláusulas coexistentes con las normas de conflicto expresamente establecidas para regular una materia concreta, que aportan soluciones generales o de carácter subsidiario, constituyendo, a la vez, un complemento, de carácter corrector, de dichas normas.

\subsection{Obligaciones}

\subsubsection{Obligaciones contractuales}

17. La inmensa mayoría de las disposiciones especiales que reafirman los poderes del juez con el establecimiento de cláusulas de excepción están contenidas en el sector de los contratos en función del peso que posee el principio de la autonomía de la voluntad de los contratantes. Concretamente la interacción entre estas cláusulas y el resto de criterios de conexión en las

66 Por el ejemplo, esta técnica también es practicada por la LDIPr polaca de 4 de febrero de 2011 en los supuestos de imposibilidad material de aplicar el Derecho extranjero (art. 10.1). Véase PAJOR, T., «Introducción a la nueva Ley polaca de Derecho internacional privado, de 4 de febrero de 2011 (seguida del texto de la ley traducido al inglés)», REDI, vol. LXIV, 2012, pp. 263 y ss.

67 Véase KoKkini-Iatridou, D., «Les clauses d'exception...», op. cit., nota 21, p. 5. 
normas sobre ley aplicable a los contratos internacionales a falta de elección conforma uno de los sectores más controvertidos del régimen de la contratación internacional.

Siguiendo la trayectoria trazada por el art. 4.5 del Convenio de Roma de $1980^{68}$, de reconocer una cláusula de excepción, y pese a que durante el proceso de conversión en el RR I se intentó por parte de la Comisión suprimirla ${ }^{69}$, este último instrumento ha sido consciente de la dificultad de la determinación de la ley aplicable en determinados supuestos y de la necesidad de que los jueces contaran con dispositivos adecuados que les permitiese un resultado justo y equitativo a través de la flexibilidad en la elección de la ley y de la previsibilidad de los resultados ${ }^{70}$. El recurso a esta técnica se ha proyectado en diversos sectores de la materia regulada. Uno de mayor amplitud, cual es el de la ley aplicable en defecto de sumisión expresa, y otros de carácter sectorial vinculados a determinadas modalidades contractuales (v. gr., contrato de transporte ${ }^{71}$ o contrato de trabajo).

18. El RR I presta una especial atención a la ley aplicable en defecto de sumisión de las partes estableciendo una válida identificación de esta última en las normas y presunciones contenidas en el art. 4. Pese a ello el legislador comunitario ha estimado oportuno establecer mecanismos correctores a la localización; por esta razón el precepto incorpora en su apartado 3 una cláusula de excepción ${ }^{72}$ considerando la posibilidad de que el contrato presente vínculos manifiestamente más estrechos con un país distinto del indicado en los apartados 1 y 2 de este precepto, y para determinar dicho país debe tenerse en cuenta, entre otros aspectos, si el contrato en cuestión tiene una relación muy estrecha con otro contrato o contratos. Nótese que la inclusión de la expresión «manifiestamente» que no figuraba en el art. 4.5 del Convenio de Roma refuerza el carácter excepcional de la cláusula restringiéndose el po-

68 De Miguel Asensio, P., «La ley aplicable en defecto de elección a los contratos internacionales: el art. 4 del Convenio de Roma de 1980», Diario La Ley, 4 de abril de 1995, pp. 1-7, http://eprints.ucm. es/6899/1/ART4CR1995.pdf; id., "Contratación internacional: La Evolución del modelo de la Unión Europea», Revista Mexicana de Derecho internacional privado y comparado, 2011, núm. 29, pp. 67-89; id., "The Law Applicable to Contractual Obligations: the Rome I Regulation in Comparative Perspective», en Basedow, J. y PißLer, K. B. (eds.), Private International Law in Mainland China, Taiwan and Europe, Tubinga, Mohr Siebeck, 2014, pp. 191-219; Garcimartín AlfÉrez, F. J., "El Reglamento "Roma I" sobre ley aplicable a las obligaciones contractuales ¿Cuánto ha cambiado el Convenio de Roma de 1980?», Diario La Ley, 2008, núm. 6957.

69 Véase la tesis doctoral de MARTínez LunA, W. F., La ley aplicable a los contratos internacionales en defecto de elección. El artículo 4 del Reglamento Roma I, Getafe, Universidad Carlos III, 2012, http://earchivo.uc3m.es/bitstream/handle/10016/15110/williamf_martinez_luna_tesis.pdf?sequence=1, pp. 374 y ss.

70 Solomon, D., «The International Law of Contracts in Europe: Advances and Retreats», Tulane L. Rev., vol. 82, 2008, núm. 5, pp. 1709-1740, esp. p. 1721.

71 Art. 5.3 RR I: «Si del conjunto de circunstancias se desprende que el contrato, a falta de elección de la ley, presenta vínculos manifiestamente más estrechos con un país distinto del indicado en los apartados 1 o 2, se aplicará la ley de ese otro país».

72 Art. 4.3 RR I: «Si del conjunto de circunstancias se desprende claramente que el contrato presenta vínculos manifiestamente más estrechos con otro país distinto del indicado en los apartados 1 o 2, se aplicará la ley de este otro país». 
der discrecional del juez. En segundo lugar, exige una vinculación manifiestamente más estrecha del contrato con otro país que resulte de manera clara e inequívoca dentro de las circunstancias que rodean el contrato. La nueva redacción resulta de utilidad a la hora de identificar la prestación característica en ciertos contratos de especial complejidad. Se busca con esta cláusula de excepción moderar los costes conflictuales para ambos contratantes pero sólo en casos excepcionales con el objeto de facilitar la celebración, el cumplimiento y la solución de la controversia o litigio judicial con arreglo al Derecho que suponga unos costes más moderados para ambas partes ${ }^{73}$.

Las consideraciones realizadas al valorar el contenido de las cláusulas de excepción de carácter general son aplicables en buena medida a la cláusula de excepción en el ámbito de contratos, sobre todo, porque no puede ampararse en preferencias materiales. A ello debe agregarse aquí que, en determinados supuestos, la ley prevista, especialmente la del prestador característico como regla general, puede ser aleatoria, y, en consecuencia, suponer una desviación del valor de eficiencia económica, seguridad del tráfico y previsibilidad que caracteriza la determinación de la ley aplicable a los contratos. En todo caso, dependerá del tipo y naturaleza del contrato y del alcance concreto que en cada uno de ellos presentan otras vinculaciones distintas a la del prestador característico $^{74}$.

La aplicación del art. 4 del RR I es imperativa para el juez ${ }^{75}$ pero para relegar el alcance de las normas de conflicto a través de la cláusula de excepción es menester una motivación reflexiva por parte del intérprete. Y aunque en la mayor parte de los casos será la parte interesada en la cláusula de excepción quien pondrá en marcha su propio interés, corresponde al juzgador pronunciarse acerca de la conveniencia de su aplicación y de los motivos que la justifican. Y a pesar de que dicha ley no corresponda a ninguna de las alegadas por cada parte contratante también podrá resolver la cuestión siempre que las partes hayan podido debatir, durante el proceso, acerca del criterio del juez. Situación que se extiende a un hipotético juicio en rebeldía ${ }^{76}$.

19. En la normativa de la UE se ha prestado atención, desde el Convenio de Roma de 1980, a la flexibilización de las soluciones conflictuales en las relaciones de trabajo ${ }^{77}$. Con la finalidad de mitigar la rigidez de las normas de conflicto rectoras del contrato de trabajo el RR I incorpora en su art. 8.4 otra cláusula de escape en la norma sobre ley aplicable a los contratos de

73 Carrascosa GonzÁlez, J., «La cláusula de excepción y los contratos internacionales. La crisis del principio de proximidad», Nuevas fronteras del Derecho de la Unión Europea. Liber Amicorum José Luis Iglesias Buhigues, Valencia, Tirant lo Blanch, 2012, pp. 459-470.

74 Fernández Rozas, J. C. y Sánchez Lorenzo, S., Derecho internacional privado, 8. a ed., Cizur Menor, Civitas-Thomson-Reuter, 2015, p. 544.

${ }_{75}$ STJCE (Gran Sala) de 6 de octubre de 2009 [as. C-133/08, Intercontainer Interfrigo SC (CIF)/ Balkenende Oosthuizen BV, MIC Operations BV].

76 Fernández Rozas, J. C. y SÁnchez Lorenzo, S., op. cit., nota 74, p. 545.

77 Zabalo Escudero, M. E., «Mecanismos de flexibilización y materialización en la regulación del contrato internacional de trabajo», Pacis Artes, Obra homenaje al Profesor Julio D. González, Campos, t. II, Madrid, UAM, Eurolex, 2015, esp. p. 1827. 
trabajo a falta de elección, siguiendo la línea trazada por el antiguo art. 6 del Convenio de Roma ${ }^{78}$. El art. 8 del RR I tiene en cuenta la protección del trabajador, al introducir límites materiales muy notables a la posibilidad de elegir el Derecho aplicable, en el sentido de que su validez está en función de la ley elegida, imponible por el empleador como parte fuerte, y sólo resulta de aplicación si favorece al trabajador. Dicha elección está condicionada por dos supuestos regulados en los párrs. 2 y 3 . No obstante, en ambos casos el juez tiene la posibilidad, de acuerdo con el art. 8.4, de poner en marcha una cláusula de excepción específica y, por ende, de aplicar una ley que presente vínculos más estrechos con otro país: «Si del conjunto de circunstancias se desprende que el contrato presenta vínculos más estrechos con un país distinto del indicado en los apartados 2 o 3, se aplicará la ley de ese otro país». Al igual que acontece con el art. 4.3. Puede observarse que en el art. 8.4 del RR I, la cláusula de excepción parece formularse con menor rigor pues se omite el adverbio «manifiestamente», habilitando una mayor flexibilidad.

La aplicación práctica de este último precepto es bastante frecuente en los contratos de embarque en los que estén involucrados buques bajo pabellones de conveniencia. A ello responde la Sentencia del Juzgado de lo Social de Bilbao, de 29 de septiembre de 2014 que, a propósito de un contrato de trabajo celebrado en España para buque con bandera de este tipo, consideró que la cláusula de escape del precepto citado implica

«...la necesidad de buscar la realidades fácticas en orden a evitar que por formalidades negociales queden desvirtuados los auténticos derechos aplicables, que preservan tanto la soberanía como las garantías del ciudadano, evitando el que los marcos laborales queden al arbitrio de una de las partes, integrando los puntos de conexión reales de los interlocutores. De esta forma, los diversos foros que legislativamente son aplicables, y que enumera el precepto nos conducen a una tradición en orden a los contratos de embarque que procura evitar los llamados pabellones de conveniencia y de los que pueda deducirse una conducción a ordenamientos jurídicos escasamente conectados con los criterios de la conexión, que se imponen como norma general pese a su excepcionalidad, por razón de las coyunturas a las que se atienden. Así, aunque no sólo se atienda a ese ordenamiento más protector, lo cierto es que el principio de proximidad a la realidad de las partes conduce a la búsqueda del ordenamiento eludido, como fuente real del contrato de trabajo.... ${ }^{79}$.

Tras la doctrina sentada por las SSTJ de 15 de marzo de 2011 (as. C-29/10, Koelzsch) y de 15 de diciembre de 2011 (asunto C-384/10, Voogsgeerd) en orden a los criterios de conexión previstos en defecto de elección, la STJ de 12 de septiembre de 2013 (asunto C-64/12, Schlecker) ofrece gran importancia insertando precisiones muy relevantes acerca de la interacción de dicha cláusula de escape con el resto de los criterios de conexión de esa norma, así como con respecto a los factores relevantes para determinar el país con el

${ }^{78}$ Cuya favorable acogida en su día no fue unánime, véase MaYer, P. y HeuZe, V., Droit international privé, 8. ${ }^{\mathrm{a}}$ ed., París, Montchrestien, 2004, pp. 556-557.

79 Ponente: Ilma. Sra. D. a María Ángeles González González, AS/2014/2923. 
que un contrato de trabajo tiene los vínculos más estrechos ${ }^{80}$. En particular, para el TJ entre los elementos significativos de vinculación debe tenerse en cuenta especialmente «el país en el que el trabajador por cuenta ajena paga sus impuestos y los tributos que gravan las rentas de su actividad y aquel en el que está afiliado a la seguridad social y a los distintos regímenes de jubilación, seguro por enfermedad e invalidez». Asimismo, el TJ considera que el juez deberá considerar también «la totalidad de las circunstancias del asunto, como, en particular, los parámetros relacionados con la fijación del salario u otras condiciones de trabajo». El Tribunal toma, pues, partido en la controvertida cuestión de la materialización de la cláusula de escape y se inclina por respaldar la ausencia en las mismas de consideraciones de orden material, reafirmando su carácter neutral y su vinculación al principio de proximidad. De esta suerte, al cumplir una mera función localizadora desaparece la posibilidad de utilizar la cláusula como mecanismo de protección del trabajador ${ }^{81}$. Una solución que no puede compartirse.

\subsubsection{Obligaciones extracontractuales}

20. Este sector en los últimos tiempos ha registrado la presencia de numerosas cláusulas de excepción, que no han contado con todos los parabienes de la doctrina. Diversos sistemas de DIPr estatales incorporan cláusulas de excepción a la regla general de la lex loci delicti commissi (véase el art. 48.2 in fine de la Ley austriaca de 1978 que dispone que si las personas involucradas tienen conexión más estrecha con la ley de un Estado determinado, se aplicará dicha ley). Es obvio que tal incorporación está en principio justificada, pero puede resentirse en algunos casos concretos como el de la responsabilidad por contaminación transfronteriza donde la cláusula puede frustrar la finalidad de protección de las víctimas del daño ${ }^{82}$.

21. El Reglamento (CE) núm. 864/2007, de 27 de julio, relativo a la ley aplicable a las obligaciones extracontractuales (RR II), al lado de la regla general y de las reglas específicas proyectadas para conseguir los objetivos de localización, incluye en alguna de sus disposiciones cláusulas de escape que, como afirma el cdo. 14, permiten al juez «apartarse de estas reglas cuando se desprenda claramente de todas las circunstancias del caso que el hecho dañoso está manifiestamente más vinculado con otro país. Este conjunto de

80 De Miguel Asensio, P. A., Principio de proximidad, cláusula de escape y protección del trabajador en la contratación internacional, 18 de septiembre de 2013, http://pedrodemiguelasensio.blogspot.com. es/2013/09/principio-de-proximidad-clausula-de.html.

81 Véanse las notas a esta decisión de PARAdela Areán, P., «Ley aplicable al contrato individual de trabajo y determinación de los vínculos más estrechos (Comentario a la STJ de 12 septiembre 2013)», La Ley: Unión Europea, 2014, núm. 14, pp. 41-46; id., "Contrato de trabajo que presenta vínculos más estrechos con otro Estado miembro», AEDIPr, t. XIII, 2013, pp. 1073-1076.

82 Palao Moreno, G., La responsabilidad civil por daños causados al medio ambiente: aspectos internacionales, Valencia, Universitat de València, 1998, p. 123; VINAIXA MIQUEL, M., La responsabilidad civil por contaminación transfronteriza derivada de residuos, Santiago de Compostela, De Conflictus Legum, Estudios de Derecho Internacional Privado, 2006, p. 237. 
reglas crea de esta manera un marco flexible de normas de conflicto de ley. Del mismo modo, permite al órgano jurisdiccional competente tratar los casos individuales de forma adecuada». Esta solución puede valorarse positivamente, pues una aplicación mecánica de la lex loci delicti (art. 4.1) o de la ley de la residencia habitual común del causante del daño y de la persona perjudicada (art. 4.2) puede no ser apropiada en ciertos supuestos específicos. La existencia de la cláusula, al igual que acontece con el RR I, también se justifica como la exclusión del reenvío. El art. 4.3 insiste en el carácter excepcional de su puesta en marcha mitigando la valoración de la incidencia de los vínculos en los supuestos en que queda claramente establecida la mayor vinculación con otro ordenamiento ${ }^{83}$. Por último, el art. 4.3 presenta una diferencia sustancial en relación con las cláusulas de excepción de alcance general que siguen el modelo trazado por el art. 15 de la LDIPr suiza en el sentido de que renuncia al doble test referido a la verificación de ausencia de vínculos estrechos con la ley aplicable y a la existencia de vínculos más estrechos con otro ordenamiento ${ }^{84}$.

Pese a que el Reglamento incluye reglas específicas en varias situaciones particulares (actos que restrinjan la libre competencia, daños medioambientales o infracciones a los derechos de propiedad intelectual) no cubre todas las hipótesis posibles. Curiosamente en estas materias no rige la cláusula de excepción apuntándose que no existen razones suficientes para sostener que las reglas especiales que rigen en la materia no puedan quedar afectadas por vínculos más estrechos con otro posible ordenamiento ${ }^{85}$.

De hecho, la lex loci delicti commissi es una de las conexiones más susceptibles de ser corregidas a través de una cláusula de excepción. No es raro que se designe un ordenamiento absolutamente imprevisible para las partes, carente de proximidad alguna con el supuesto. De ahí que el art. 4.3 del RR II prevea que «si del conjunto de circunstancias se desprende que el hecho dañoso presenta vínculos manifiestamente más estrechos con otro país distinto del indicado en los apartados 1 o 2, se aplicará la ley de este otro país. Un vínculo manifiestamente más estrecho con otro país podría estar basado en una relación preexistente entre las partes, como por ejemplo un contrato, que esté estrechamente vinculada con el hecho dañoso en cuestión».

El precepto permite al juez solucionar muchas cuestiones concretas que dejan en el aire las normas de conflicto contenidas en el Reglamento pero la flexibilidad que incorpora debe utilizarse con mesura pues el juez para apartarse de las conexiones debe valorar muy estrictamente las circunstancias del caso en el sentido de que el hecho dañoso debe poseer con carácter manifiesto mayor vinculación a otro país. Además, despliega una cierta eficacia, en determinados supuestos en que preexiste una relación contractual, por lo

\footnotetext{
83 De Miguel Asensio, P. A., «El régimen comunitario relativo a la ley aplicable a las obligaciones extracontractuales», Revista Española de Seguros, 2009, núm. 140, pp. 695-726.

${ }^{84}$ Véase Bucher, A., "La dimension sociale du droit international privé. Cours général», Recueil des Cours, t. 341, 2009, p. 213.

85 Amores Conradi, M. A. y Torralba Mendiola, E., "XI tesis sobre el estatuto delictual», REEI, 2004, núm. 8, p. 11.
} 
que se ha defendido la aplicación, por accesoriedad, de la ley rectora de la relación contractual (transporte, servicio médico, etc.) a la que se vincula la responsabilidad por daños, como ley más estrechamente vinculada. También resuelve el régimen de los daños que se producen en espacios internacionales o no sujetos a la soberanía estatal (alta mar, espacio ultraterrestre, etc.). Por último la cláusula de excepción tiene un importante papel que jugar en lo relacionado con los accidentes en masa ${ }^{86}$.

22. La culpa in contrahendo ${ }^{87}$ se configura en el art. 12 del RR II como un concepto autónomo que incluye la violación del deber de información y la ruptura de los tratos contractuales. Dicho precepto cubre únicamente las obligaciones extracontractuales con vínculo directo con los tratos previos a la celebración de un contrato estableciendo al efecto una conexión principal en el párr. 1, «la ley aplicable al contrato o la que se habría aplicado al contrato si este se hubiera celebrado" y dos conexiones particulares en las letras a) y b) del párr. 2 en caso de que dicha ley no pueda determinarse: la ley de la residencia habitual común de las partes en el momento en que tiene lugar el hecho generador del daño, o en su caso, a la ley del país en que se hubiera producido el daño directo, con independencia del país en que radique el acontecimiento causal o el hecho generador del daño. Pero el precepto añade una letra $c$ ) en dicho párrafo que incorpora una cláusula de escape en el sentido de que «si del conjunto de las circunstancias se desprende que la obligación extracontractual que se derive de los tratos previos a la celebración de un contrato presenta vínculos manifiestamente más estrechos con otro país distinto del indicado en las letras $a$ ) y b), se aplicará la ley de este otro país».

Como puede desprenderse de la regulación del art. 12, la aplicación de la cláusula de escape que incluye es muy limitada. De un lado, se restringe a las situaciones en las cuales la ley aplicable se determina de acuerdo con las reglas del párr. 2 por lo que no tendrá operatividad cuando la ley que rige la culpa in contrahendo se determina de acuerdo con la regla general del párr. 1. De otro lado, la cláusula únicamente será de aplicación cuando la lex contractus del negocio no pueda determinarse y no lo será cuando dicha ley parezca estar suficientemente vinculada al supuesto. Además, la cláusula no podrá ser utilizada para desplazar la lex contractus del negocio cuando conduzca a resultados inapropiados ${ }^{88}$.

\subsection{Persona}

23. En el seno de la Conferencia de La Haya de DIPr la protección de los niños y la protección de los adultos han tenido una vida en cierta medida

\footnotetext{
86 Fernández Rozas, J. C. y Sánchez Lorenzo, S., op. cit., nota 74, pp. 594-595.

87 Moura Vicente, D., "La culpa in contrahendo en el Derecho internacional privado europeo», AEDIPr, t. XIII, 2013, pp. 53-72.

${ }^{88}$ Hage-Chahine, N., "Culpa in Contrahendo in European Private International Law: Another Look at Article 12 of the Rome II Regulation», Northwestern J. Int'l L. Buss., 2012, pp. 451-540, esp. p. 529, http://scholarlycommons.law.northwestern.edu/cgi/viewcontent.cgi? article=1025\&context=njilb.
} 
paralela, lo cual, como afirmase A. Borrás, es sintomático tanto de la evolución de los tiempos como del DIPr ${ }^{89}$. Precisamente este sector ofrece un importante campo de actuación para las cláusulas de excepción, de lo que ha sido consciente la propia Conferencia. Por esta razón el Convenio de La Haya de 19 de octubre de 1996 relativo a la competencia, la ley aplicable, el reconocimiento, la ejecución y la cooperación en materia de responsabilidad parental y de medidas de protección de los niños incluye un bloque de normas conflictuales en los arts. 15 a 22 cuya aplicación tiene carácter universal para los Estados miembros (art. 20). El art. 15.1 establece una regla de base caracterizada por la vinculación forum/ius y concretada en el postulado de aplicación a las medidas de protección del menor de la lex fori (art. 15.1), un postulado que responde a que la proximidad del interés descansa en normas de competencia judicial internacional supeditadas a la residencia habitual del menor y a facilitar la labor de la autoridad que conoce del caso, que aplicará así la ley que conoce mejor ${ }^{90}$. Sin embargo, precisada la conexión el párr. 2 de este precepto incorpora una cautela en forma de cláusula de excepción según la cual «en la medida en que la protección de la persona o de los bienes del niño lo requiera, pueden excepcionalmente aplicar o tomar en consideración la ley de otro Estado con el que la situación tenga un vínculo estrecho». Como puede observarse, esta cláusula de excepción reposa no en el principio de proximidad, sino en el interés superior del niño ${ }^{91}$.

El apuntado paralelismo regulador tiene una traducción exacta en el art. 13 del Convenio de 13 de enero de 2000 sobre protección internacional de los adultos y aunque España no sea parte del mismo, sirve para reforzar el juego de la cláusula, justificada, en este caso, en interés del adulto ${ }^{92}$.

\subsection{Familia y sucesiones}

24. La determinación del principio de proximidad en el ámbito de las relaciones de familia depende de una serie de elementos objetivos, por lo general suficientemente delimitados en las normas de conflicto con conexiones

89 BorRás, A., «La protección internacional del niño y del adulto como expresión de la materialización del Derecho internacional privado: similitudes y contrastes», Pacis Artes, Obra homenaje al Profesor Julio D. González Campos, t. II, Madrid, UAM, Eurolex, 2015, núm. 6, p. 1287.

90 Lagade, P., Informe explicativo, p. 43, http://www.hcch.net/upload/expl34s.pdf.

91 Ibid., p. 44. «El ejemplo más frecuentemente citado es el de la autorización pedida a las autoridades de la residencia habitual para vender un bien del menor situado en el extranjero. Es seguramente preferible que la autoridad a que se acude puede en tal caso aplicar la lex situs rei y conceder la autorización prevista por ésta, ley real, incluso si la ley de la autoridad a que se acude no exige en la materia autorización alguna. Podría también indicarse la aplicación de su ley nacional a la protección de niños extranjeros si resulta que estos niños van a volver en plazo breve a su país de origen».

92 Lagarde, P., Rapport explicatif, pp. 52-53, http://www.hcch.net/upload/expl35e.pdf: si se solicita una autorización de las autoridades de la residencia habitual para vender bienes del adulto situados en el extranjero, es preferible que la autoridad que ejerza jurisdicción pueda aplicar o tomar en consideración la ley del lugar de la propiedad y otorgar la autorización prevista en dicha ley, incluso si la ley de la autoridad que ejerce la jurisdicción no requiere una autorización en tal caso. 
de carácter abstracto como la nacionalidad, domicilio o residencia habitual común que, en muchas ocasiones, ignora que muchos extranjeros residentes en un país guardan una relación muy estrecha con su país de origen, circunstancia acompañada por un rechazo a cualquier modalidad de integración y por un manifiesto espíritu de retorno. En estos casos, por ejemplo, el recurso a la ley nacional previsto en la norma de conflicto puede contradecir la apreciación de los vínculos más estrechos. En la construcción de la excepción la discrecionalidad del juez es determinante al estar condicionada por sus propias convicciones ${ }^{93}$; una buena aplicación de la cláusula en este especial sector exigiría de éste la precisión cumulativa de la debilidad de los vínculos con el Derecho designado por la norma de conflicto y de la fortaleza de dichos vínculos con el ordenamiento que considera debe ser aplicado. Que concurra una de ellas no implica necesariamente que la otra también esté presente por lo cual la excepción no podría tener lugar.

En el sector que estamos examinando es frecuente la distorsión entre lo dispuesto en las normas de conflicto de un determinado sistema y la proximidad real del supuesto con el ordenamiento más vinculado, por lo que es un terreno abonado para el empleo de las cláusulas de excepción. Concretamente en este sector el juez antes de poner en marcha la cláusula deberá tener completa constancia de la debilidad de los vínculos de la ley designada.

25. La acción de las cláusulas de excepción en el ámbito de las sucesiones internacionales, pese a no tener la importancia alcanzada en materia contractual, ha sido propugnado desde hace años con la pretensión de corregir la aplicación de la ley del último domicilio del causante, por medio de la ley de la nacionalidad de éste, en aquellos casos en los que la mayor parte de los bienes se encuentren en el país designado por esta última conexión y con el objetivo preciso de asegurar la eficacia de las decisiones en el espacio ${ }^{94}$.

Con todo, la técnica se ha extendido también a este sector a pesar de que los textos que las incluyen han tenido la oportunidad de establecer normas de conflicto con un evidente grado de precisión ${ }^{95}$. Tal es el caso del Convenio de La Haya de 1 de agosto de 1989 sobre la ley aplicable a las sucesiones por causa de muerte que incorpora una cláusula de excepción de carácter restrictivo que posibilita desplazar la ley de la residencia habitual por la ley de la nacionalidad (art. 3.2: «En circunstancias excepcionales, si el difunto tuviera en el momento de su fallecimiento vínculos manifiestamente más estrechos con el Estado del que en ese momento fuera nacional, se aplicará la ley de este último Estado») y otra de mayor amplitud que admite la posibilidad de sustituir la ley de la nacionalidad del difunto por la ley con la cual tenía vínculos más

93 Ballarino, T. y Romano, G. P., «Le principe de proximité chez Paul Lagarde», Le droit international privé: esprit et méthodes. Mélanges en l'honneur de Paul Lagarde, París, Dalloz, 2005, pp. 37 y ss., esp. p. 42.

94 Dubler, C., Les clauses d'exception..., op. cit., nota 49, p. 100.

95 DutTa, A., "Succession and Wills in the Conflict of Laws on the Eve of Europeanisation», $R a$ belsZ, t. 73, 2009, pp. 547-606. 
estrechos (art. 3.3: «Si en ese momento el difunto tuviera vínculos más estrechos con otro Estado, en cuyo caso se aplicará la ley de este último»). Pese a que las reglas descritas han sido criticadas por su inseguridad y excesiva complejidad y por complicar la tarea de la autoridad que debe aplicarlas ${ }^{96}$, no puede negarse que acaso el escaso éxito de este instrumento internacional puede obedecer a esta circunstancia flexibilizadora ${ }^{97}$.

También en el proceso de codificación del DIPr europeo se ha incorporado esta técnica tras la entrada en vigor del Reglamento (UE) 650/2012, del Parlamento Europeo y del Consejo, de 4 de julio, relativo a la competencia, la ley aplicable, el reconocimiento y la ejecución de las resoluciones, a la aceptación y la ejecución de los documentos públicos en materia de sucesiones mortis causa y a la creación de un certificado sucesorio europeo. El art. 21 del Reglamento, tras designar en el párr. 1 del art. 21 la aplicación de la ley de la residencia habitual del causante en el momento del fallecimiento, introduce en el párr. 2 una cláusula de excepción al determinar que «si, de forma excepcional, resultase claramente de todas las circunstancias del caso que, en el momento del fallecimiento, el causante mantenía un vínculo manifiestamente más estrecho con un Estado distinto de aquel cuya ley fuese aplicable de conformidad con el apartado 1, la ley aplicable a la sucesión será la de ese otro Estado». La referida cláusula no puede ser utilizada de manera indiscriminada cuando la determinación de la residencia habitual ofrezca cierta dificultad, ni emplearse como una técnica de solución de carácter subsidiario ${ }^{98}$.

Cabe reiterar que, como es consustancial a toda cláusula de excepción, la aplicación de este precepto sólo es factible cuando se determine la ley aplicable a la sucesión conforme a la norma objetiva, esto es, cuando no haya habido elección de ley por parte del causante. Como es previsible en la inmensa mayoría de los supuestos la ley más estrechamente vinculada al causante sustitutoria de la de su residencia habitual en el momento de su fallecimiento será la ley correspondiente a su nacionalidad ${ }^{99}$.

96 Bonomi, A., «Successions internationales: conflits de lois et de juridictions», Recueil des Cours, t. 350, 2011, pp. 189-190.

97 LI, H., "Some Recent Developments in the Conflicts of Laws in Succession», Recueil des Cours, t. 224, 1990-V, pp. 9-122, esp. p. 51; von Overbeck, A. E., «La contribution de la Conférence de La Haye au développement du droit international privé», Recueil des Cours, t. 233, 1992-II, pp. 9 y ss., esp. p. 76; Lequette, Y., "Le droit international privé de la famille à l'épreuve des conventions internationales», Recueil des Cours, t. 246, 1994-II, pp. 9 y ss., esp. pp. 178 y ss.

98 De acuerdo con el Cdo. 25 de este Reglamento, «en casos excepcionales en los que, por ejemplo, el causante se haya mudado al Estado de su residencia habitual poco tiempo antes de su fallecimiento, y todas las circunstancias del caso indiquen que aquél tenía un vínculo manifiestamente más estrecho con otro Estado, la autoridad que sustancie la sucesión puede llegar a concluir que la ley aplicable a la sucesión no sea la ley del Estado de residencia habitual del causante sino la ley del Estado con el que el causante tenía un vínculo manifiestamente más estrecho. No obstante, la vinculación manifiestamente más estrecha no debe emplearse como nexo subsidiario cuando la determinación de la residencia habitual del causante en el momento de su fallecimiento resulte compleja».

99 Rodríguez-Uría SuÁRez, I., "La ley aplicable a las sucesiones mortis causa en el Reglamento (UE) 650/2012», Indret, Revista para el Análisis del Derecho, 2/2013. 


\section{LA CLÁUSULA DE EXCEPCIÓN COMO MECANISMO DE REALIZACIÓN DE OBJETIVOS MATERIALES}

26. Cuando hablamos de cláusulas de excepción en relación con el método de localización estamos en presencia de un correctivo a la localización cuya finalidad no es entorpecer sino, por el contrario, mejorar el mandato de la norma de conflicto eliminando la rigidez que puede caracterizarla, bien es verdad que en detrimento del valor "seguridad jurídica», en el sentido de aportar menor certidumbre y menor previsibilidad. Ciertamente, las cláusulas de excepción de alcance general no establecen unos criterios definidos que permitan llevar al convencimiento del juez de las razones que justifican la derogación del mandato contenido en la norma de conflicto o que posibiliten medir si el vínculo es débil o fuerte y, además, hay que tener presente que no siempre la ley que presenta los vínculos más estrechos con el supuesto es la más apropiada. Pese a estas reticencias las cláusulas de excepción proyectadas a situaciones concretas han demostrado su operatividad, de ahí su acogida favorable como importante elemento corrector y mecanismo óptimo de especialización en razón del grado de heterogeneidad; diversificación que va más allá incluso de la que reflejan las normas a las que eventualmente excepciona.

Dentro de las múltiples facetas de la flexibilización se encuentra una que, sin abandonar el proceso de localización, hace frente a la rigidez de las conexiones de la norma de conflicto, que en determinadas circunstancias pueden designar un ordenamiento jurídico con escasa vinculación con el supuesto produciendo situaciones indeseables. El empleo de una cláusula de excepción en este caso contribuye a afianzar la certeza y previsibilidad necesarias en una norma de conflicto y, con ello, la satisfacción del principio de proximidad. Sin embargo, ello no lleva aparejado que las cláusulas de excepción ostenten por esta circunstancia una significación sustancial o constituyan un procedimiento autónomo para alcanzar una solución justa ${ }^{100}$.

La proximidad es sólo una imagen, expresiva sin duda, pero sólo eso. Las dicciones tales como "conexión más estrecha», "otra ley más vinculada», o «agrupación de contactos», se limitan a realizar una medición puramente cuantitativa de los elementos de conexión, por lo que resulta menester, a partir de aquí, indagar en los criterios que deben utilizarse para practicar una valoración adecuada de dichos elementos. Por consiguiente, si la localización del Derecho designado por la norma de conflicto y la puesta en marcha del principio de proximidad se entienden en clave material, la cláusula de excepción funcionará con toda eficacia, pues no actuará como un simple instrumento de orientación material, sino como una técnica localizadora, dentro del mecanismo conflictual, que busca la solución justa teniendo en

100 SÁnchez Lorenzo, S., «Postmodernismo e integración en el Derecho internacional privado de fin de siglo», Cursos de Derecho internacional de Vitoria-Gasteiz, 1996, Madrid, Tecnos, 1997, pp. 149-173. 
cuenta los objetivos materiales que se pretenden en la solución del caso concreto.

\title{
RESUMEN
}

\author{
FUNCIONES DE LAS CLÁUSULAS DE EXCEPCIÓN EN EL PROCESO \\ DE LOCALIZACIÓN DE LA NORMA DE CONFLICTO
}

Una importante faceta de la flexibilización es aquella que, sin abandonar el proceso de localización, hace frente a la rigidez de las conexiones de la norma de conflicto, que en determinadas circunstancias pueden designar un ordenamiento jurídico con escasa vinculación con el supuesto produciendo situaciones indeseables. En su consecución ciertos textos de la codificación interna e internacional de Derecho internacional privado han recurrido a la denominada "cláusula de excepción» a partir de la cual el juez cuenta con una "potestad institucionalizada» para determinar la ley aplicable, siempre que la situación presente inequívocamente "vínculos más estrechos» con otro orden jurídico del designado por la norma de conflicto. Las cláusulas de excepción proyectadas a situaciones concretas han demostrado su operatividad, de ahí su acogida favorable como importante elemento corrector y mecanismo óptimo de especialización en razón del grado de heterogeneidad. Su empleo contribuye a afianzar la certeza y previsibilidad necesarias de las normas de conflicto y, con ello, la satisfacción del principio de proximidad. Ahora bien, esta localización debe entenderse en clave material. La cláusula de excepción funcionará con toda eficacia si actúa como una técnica localizadora, dentro del mecanismo conflictual, que busca la respuesta justa teniendo en cuenta los objetivos materiales que se pretenden en la solución del caso concreto.

Palabras clave: conflicto de leyes, puntos de conexión, localización, flexibilización, cláusulas de excepción.

\section{ABSTRACT \\ FUNCTIONS OF THE EXCEPTION CLAUSES IN THE LOCALISATION PROCESS OF CONFLICT OF LAWS RULES}

An important aspect of flexibility is that, without abandoning the localisation process, it counteracts the rigidity of the connections of the conflict of law rules that may appoint, in certain circumstances, a legal system with weak links to the case and may give rise to undesired results. In the national and international codification of private international law, some texts have turned to a so-called «exception clause» which allows judges to have the institutionalized power to determine the applicable law, as long as the situation has an unequivocally "closer connection» with another law other than the one designated by the conflict of law rule. The exception clauses designed for specific situations have proved to be useful and, therefore, have been welcomed as an important correction instrument and as an excellent mechanism for specialisation in accordance with the degree of heterogeneity. Its use helps to consolidate the necessary certainty and predictability of the conflict of law rules and, therefore, the satisfaction of the proximity principle. Obviously, this localisation must be understood in a material sense. The exception clause will deploy its usefulness if it acts as a localisation technique included in the conflictual mechanism that seeks the right answer, taking into account the material objectives sought in the solution of the case.

Keywords: Conflict of Laws, Connecting Factors, Localisation, Flexibilisation, Exception Clauses. 


\section{RÉSUMÉ}

\section{FONCTIONS DES CLAUSES D'EXCEPTION DANS LE PROCESSUS DE LOCALISATION DE LA RÈGLE DE CONFLIT}

Un aspect important de la flexibilisation est celle qui, sans abandonner le processus de localisation, contrecarre la rigidité des rattachements de la règle de conflit qui peuvent conduire, dans certaines circonstances, à un système juridique avec des liens faibles avec le cas d' l'espèce et produire des situations indésirables. Dans la poursuite de cet objectif certains textes de codification nationale et internationale du droit international privé se sont tournés vers la soi-disant «clause d'exception» à partir de laquelle le juge a un pouvoir institutionnalisé pour déterminer la loi applicable, chaque fois que la situation offre sans équivoque un lien plus étroit avec un autre ordre juridique de ce désigné par la règle de conflit. Les clauses d'exception conçues pour des situations spécifiques se sont révélées utiles et, par conséquent, ont été bien accueillis comme un instrument correcteur important et comme le meilleur mécanisme pour la spécialisation en raison du degré d'hétérogénéité. Sa utilisation contribue à consolider la certitude nécessaire et la prévisibilité des règles de conflit et donc la satisfaction du principe de proximité. Bien entendu que cette localisation doit être compris dans un sens à caractère matérielle. La clause d'exception va déployer toute son utilité si elle opère comme une technique de localisation à l'intérieur du mécanisme conflictuelle, qui cherche la réponse juste, compte tenu des objectifs matériels qui recherche pour la solution de l'affaire.

Mots-clés: conflit de lois, points de rattachement, flexibilisation, localisation, clauses d'exception. 